\title{
O que torna Darwin dramático? Mário Montenegro
}

Apesar de ser um

fenómeno recente, vários

estudos referem-se às peças de teatro de tema cientifico ("science plays" ou "science-in-theatre") como configurando um

novo subgénero

dramático. Ver a este respeito Djerassi (2002) Shepherd-Barr (2006)

Montenegro (2007) Zehelein (2009).

${ }^{2}$ Informação sobre 0 programa de promoção

da cultura cientifica

através do teatro $d$ Alfred Sloan Foundation pode ser encontrada aqui: http://www.sloan.org/pr ogram/24 [consultado em

16.10.2011]

${ }^{3}$ Curiosamente, a ideia inicial dos organizadores das comemorações seria produzir um espectáculo

baseado na peça de

Jerome Lawrence e Rober E. Lee Inherit the Wind

Sobre a Darwin

Centennial Celebration ver Smocovitis (1999).

Mário Montenegro é Mestre em Texto

Dramático pela

Faculdade de Letras da Universisdade do Porto

e doutorando em

Estudos Artísticos n Faculdade de Letras d

Universidade de

Coimbra

É actor, encenador director artístico da companhia de Teatro marione

\section{Ciência no Teatro}

Por volta dos anos 80/90 do século XX houve uma espécie de big bang no teatro. Desde essa altura o número de peças que explora temas da ciência tem vindo a expandirse de modo exponencial. Uma diferença essencial entre este big bang e a teoria homónima que tenta explicar o começo do universo é que neste caso já algo existia antes da explosão. É possivel assinalar algumas peças de teatro que anteriormente já integravam temas científicos nos seus enredos, mas estas peças são, no contexto da produção dramática global , ( - continuando com a analogia astrofísica - ) uma espécie de radiação de fundo no sentido de algo que já existia mas que, a determinada altura, ganhou um significado específico. Exemplos bem conhecidos são a Vida de Galileu, de Bertolt Brecht (1938 [1970]), ou Os físicos, de Friedrich Dürrenmatt (1962 [1965]). As duas peças estão ancoradas nas figuras de importantes cientistas da nossa história e, entre outras coisas, reflectem sobre a responsabilidade social dos cientistas como individuos e, através deles, sobre a mais universal responsabilidade da Ciência.

Este fenómeno, nalguns casos bastante alicerçado e impulsionado pela comunidade científica, tem tido ramificações interessantes, nomeadamente através de acontecimentos paralelos à peça de teatro, como sejam os colóquios e conferências em torno não só do texto dramático mas também dos assuntos científicos por ele abordados. Há, através deste subgénero teatral ${ }^{1}$, uma aproximação das tradicionais "duas culturas" (Snow 1959). E esta é uma aproximação prática, em que diferentes linguagens e métodos de transmissão de conhecimentos destes dois campos se relacionam e interpenetram.

Mas porquê este súbito interesse do Teatro por temas científicos? E porquê neste momento? A motivação para este encontro parte dos dois intervenientes. Do lado da Ciência, a vontade de uma maior e mais próxima interacção com a sociedade tem-na levado a procurar novas formas de comunicação (Djerassi 2002, Rose 2003), sendo o Teatro ou, em muitos casos, a dramatização de questões, personagens ou acontecimentos científicos, algumas das formas que encontrou para o fazer. A apresentação de pequenas peças dramáticas em conferências e congressos científicos, a oferta de representações em torno da Ciência por parte de museus e centros de ciência, são exemplos desse esforço consciente de aproximação à sociedade por parte da Ciência (Magni 2002, Begoray 2005). Um caso exemplar é o da fundação norte-americana Alfred P. Sloan que desde 1998 financia a criação e produção de peças de teatro de tema científico e tecnológico ${ }^{2}$. Assim como o são os casos de cientistas-escritores que decidem expor questões relacionadas com a Ciência sob a forma de texto dramático - como fazem, por exemplo, o químico norteamericano Carl Djerassi ou o físico canadiano John Mighton.

Do lado do Teatro, os dramaturgos abordam a Ciência não só sob o ponto de vista de uma análise ética ou das suas consequências, como no caso das referidas obras de Brecht e Dürrenmatt, mas parece existir também uma introdução da Ciência nas obras dramáticas por estarem criadas as condições para uma melhor aceitação, por parte do público de teatro, dos temas e linguagens científicos facto a que não será alheia a generalização de certos assuntos pelos meios de comunicação social.

Os dramaturgos, poderão também encontrar na Ciência uma fonte de novos mitos e metáforas, e, eventualmente, uma visão mais profunda do ser humano no universo (Shepherd-Barr 2003, Barnett 2005); poderá ainda existi a procura, por parte dos produtores de teatro, de novos campos de actuação, não só pela pertinência e actualidade de alguns temas científicos (ligados à biologia celular, à física de partículas, à astronomia) com implicações imediatas na sociedade, mas também como forma de alargar o seu campo de financiamento, estendendo-o a instituições de indole científica e educacional, indo de encontro aos anseios de maior aproximação à sociedade destas comunidades.

\section{Darwin no Teatro}

2009 foi, sem dúvida, o ano de Darwin. Assinalaram-se 200 anos desde o nascimento do famoso naturalista inglês e 150 desde a publicação da sua obra científica mais famosa, A Origem das Espécies (Darwin 1859 [2005]). Charles Darwin renasceu através de uma miríade de acontecimentos que promoveram o seu nome, a sua vida e o seu legado para a Ciência. Em livros, conversas, performances, conferências, exposições, Darwin foi sendo mencionado, citado, explicado, inventado, eternizado, a um nível pouco usual considerando que não foi uma estrela pop.

No entanto, no mundo científico, a importante influência de Darwin foi sempre reconhecida e, desde 1909, de cinquenta em cinquenta anos, as efemérides sobre o seu nascimento e a publicação da sua mais famosa obra têm sido assinaladas de modo grandioso.

Na Darwin Centennial Celebration, organizada em 1959 pela Universidade de Chicago, o programa social incluiu a criação e apresentação de um musical sobre a vida e obra de Darwin, Time Will Tell ${ }^{3}$. No espectáculo, um êxito de público com todas as sessões esgotadas, foram representados alguns momentos importantes da vida do 


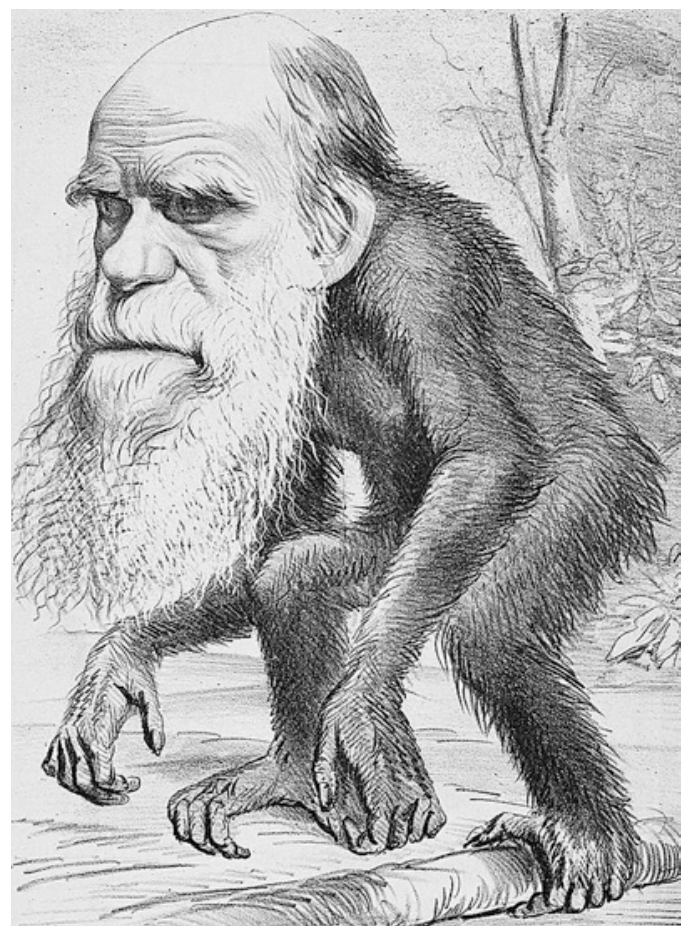

cientista, como a sua chegada no Beagle a Inglaterra, 0 momento do seu casamento, 0 início da escrita de $A$ origem das espécies, a célebre discussão na reunião da British Association for the Advancement of Science (BAAS) entre o bispo de Oxford, Samuel Wilberforce, e o biólogo Thomas Huxley, terminando com o doutoramento honorifico atribuído a Darwin pela Universidade de Cambridge. ${ }^{4}$

Mas, na verdade, como refere Janet Browne, na última fase da vida Darwin possuía muitos dos atributos de uma celebridade moderna (Browne 2003). À semelhança de Einstein, na famosa foto com a língua de fora tirada por Arthur Sasse, a imagem de Darwin foi eternizada na revista The Hornet na célebre caricatura intitulada A Venerable Orang-outang, uma imagem marcante onde o cientista e as suas teorias estão imiscuídos [imagem > caricatura Darwin].

Inevitavelmente, tal como sucede com outras importantes figuras da História da Ciência como Galileu, Newton ou Einstein, Darwin e as suas ideias também foram inspiração para dramaturgos. A proximidade das efemérides de 2009 veio aumentar a atenção de autores e companhias de teatro sobre este cientista e houve vários textos e espectáculos criados recentemente que o escolheram para tema. Neste estudo analisamos alguns dos textos dramáticos onde Darwin, as suas ideias e as respectivas consequências científicas e sociais são abordados. Para o estruturar, após uma análise das obras referidas no tocante ao modo como Darwin e as suas ideias estão presentes, dividimos os textos em três grupos. No primeiro incluímos as peças onde Darwin não está presente como personagem, apenas surgindo o legado das suas ideias; no segundo as peças onde Darwin está presente como personagem; finalmente no terceiro aquelas peças onde, para além da presença como personagem, 0 discurso De Darwin é feito com recurso às suas próprias palavras. $^{5}$

\section{Darwin através do seu legado científico}

Inherit the Wind (Lawrence 2003), uma típica "peça de tribunal [court play], não é uma peça sobre Darwin, mas sobre a repercussão das suas ideias. Escrita em 1951, foi representada pela primeira vez em 1955 no Dallas Theatre, e é baseada no famoso Scopes Trial ("Julgamento Scopes", também conhecido por Monkey Trial "Julgamento do macaco") que teve lugar em 1925 em Dayton, Tennessee, EUA. Após a aprovação de uma lei que impedia o ensino nas escolas de teorias que contrariassem o que está escrito na Biblia e afirmassem que o Homem descendia de animais inferiores - o Butler Act - o American Civil Liberties Union lançou um desafio para testar a lei oferecendo-se para defender quem ousasse ensinar a Teoria da Evolução numa escola. Um conjunto de empresários locais considerou que um julgamento desta natureza seria uma óptima oportunidade para ajudar ao desenvolvimento da pequena Dayton e convenceu o professor John Scopes a aceitar o desafio, acabando por ser julgado por isso.

Os advogados escolhidos para a acusação e a defesa no julgamento de Scopes foram os então "pesos-pesados" William Bryan e Clarence Darrow.

Jerome Lawrence e Robert E. Lee partiram deste famoso julgamento para escrever uma peça baseada em factos e personagens históricas mas com ampla liberdade artística, criando personagens fictícias.

Esta talvez seja a primeira peça de teatro a abordar o tema da Teoria da Evolução e do impacto social das ideias de Charles Darwin, embora o fito dos autores fosse abordar a questão (acesa na altura) da liberdade de pensamento e expressão na época do McCarthyism (Shepherd-Barr 2008). A actualidade da peça mantém$\mathrm{se}^{6}$ não apenas pela questão permanente da existência ou não de liberdade de expressão nas sociedades humanas, mas pelo debate entre ciência e criacionismo recentemente reactivado -, confirmando assim o vaticínio dos autores no prefácio ao texto quando afirmam

\section{"A Venerable Orang-} outang",

uma caricatura de Charles Darwin publicada na revista satirica The Hornet a 22 de Março de 1871. Créditos: domínio público, via Wikimedia Commons.

${ }^{4} 0$ programa do espectáculo pode ser encontrado na exposição virtual da Darwin Centennial Celebration em

http://www.lib.uchicago edu/e/webexhibits/Darwi nCentennial/ [consultado em 16.10.2011].

${ }^{5} 0$ agrupar das peças decorre apenas de uma opção para a estruturação deste estudo, pois permite analisar em conjunto algumas opções dramatúrgicas feitas pelos autores na transposição da vida de Darwin e das suas ideias para os textos. Não pretende criar qualquer espécie de categorização das peças.

${ }^{6}$ A peça foi remontada em 2009 no West-end Iondrino, no The Old Vic, por Kevin Spacey, que na peça representou Henry Drummond, o advogado de defesa. 
As indicações de cena apontam a época "Não há muito tempo." Pode ter sido ontem. Poderia ser amanhã. (Lawrence 2003: prefácio)

0 debate ciência vs criacionismo, surgido em grande medida como consequência do advento e difusão da Teoria da Evolução por Selecção Natural, está presente nos argumentos científicos e bíblicos esgrimidos pelos advogados de defesa e acusação respectivamente, e é um tema dramaturgicamente explorado em todos os textos estudados. Os dois livros, A origem das espécies e a Bíblia, não apenas pelas palavras que contêm, mas através da sua presença física, assumem nesta peça (assim como noutras, como veremos) um forte carácter simbólico, tornando-se adereços de cena essenciais. Em Inherit the Wind [Herdar o vento] são eles que fecham a peça:

[Drummond] pega na Biblia com a outra mão; observa os dois volumes, pesando-os pensativamente, como se as suas mãos fossem balanças. (...) Depois, junta os livros e enfia-os na pasta, lado a lado. (Lawrence 2003: 129)

Outra peça em que Darwin não é personagem, mas está presente através do legado das suas teorias é Chimera um texto de 2004 da dramaturga e ex-deputada do parlamento canadiano Wendy Lill, representado pela primeira vez em 2007 no Tarragon Theatre em Toronto. Aborda a questão da legislação sobre a investigação em células estaminais e foi inspirado na aprovação em 2004 de uma lei no parlamento canadiano que regulava as técnicas de reprodução assistida. 0 tema de fundo que atravessa a obra é o da ética na politica e na ciência. A acção decorre no presente (2004), entre o gabinete da ministra da Justiça, o Parlamento canadiano, e o jardim de uma bióloga que na sua investigação científica usa células estaminais humanas. No início do primeiro acto, Darwin serve de mote:

ROY: Nesta história apenas os mais fortes, os mais adaptados, os mais implacáveis sobrevivem. Apenas os mais engenhosos estarão de pé quando a manhã romper. A Origem das Espécies. Charles Darwin. Escreveu-o há cerca de um milhão de macacos atrás. (Lill 2007: 7)

Foi publicada uma recensão da estreia portuguesa da peça na Sinais de Cena, N. ${ }^{9}$, de Junho de 2008: Francesca Rayner, "Performance e abordados nesta obra e é tornado explícito na argumentação entre a cientista e o deputado conservador de que é exemplo a seguinte frase irónica da ministra:

CLARE: [...] Os seres humanos, incluindo Adão e Eva, caminharam lado a lado com os poderosos dinossauros e partilharam com eles o grande jardim de Deus há apenas cinco mil anos atrás. (Lill 2007 77)

Adicionalmente, Chimera, ao criar relações entre as personagens com doenças e distúrbios genéticos (o jornalista tem um irmão com a sindrome de Down, a cientista um filho que morreu com SIDA e a sua investigação tem por finalidade encontrar cura para o autismo) levanta a reflexão sobre estas questões em confronto com as ideias de evolução e sobrevivência dos mais aptos.

\section{Darwin como personagem}

$\mathrm{Na}$ maioria das peças analisadas Darwin surge como personagem. São peças que contêm uma forte base biográfica. Em After Darwin, de Timberlake Wertenbaker, representada pela primeira vez no Hampstead Theatre em Londres em 1998, e estreada em Portugal em 2007 (numa versão muito adaptada) pelo TNDM II no Teatro da Politécnica ${ }^{7}$, assistimos a uma peça dentro da peça onde o cientista é figura central. Na peça "exterior" (no tempo presente) um conjunto de artistas cria uma outra peça de teatro sobre o cientista centrada em factos biográficos do período entre 1831 e 1865 e, em particular, na sua relação com o Capitão Fitzroy, comandante do navio Beagle. A viagem no Beagle, o relacionamento entre os dois homens e a descoberta da Teoria da Evolução por Selecção Natural são o núcleo dramático central desta peça dentro da peça, e vão influenciando o comportamento das personagens do tempo presente.

Os artistas, na peça "exterior", têm todos um estatuto social de "risco". A encenadora é uma imigrante búlgara a tentar conseguir residência fixa em Inglaterra, um dos actores é homossexual, outro dos actores vem dum largo periodo sem trabalho e finalmente o dramaturgo é um afro-americano de origens humildes. As suas condições e necessidade de sobrevivência social cruzam-se, à medida que as peças vão progredindo, com a teoria de Darwin sobre a sobrevivência das espécies. Um exemplo do que acabo de referir pode encontrar-se no seguinte excerto, onde um dos actores justifica o abandono dos ensaios em favor doutro trabalho onde Ihe pagarão mais, usando para isso as ideias de Darwin que vêm descobrindo e discutindo nos ensaios: 


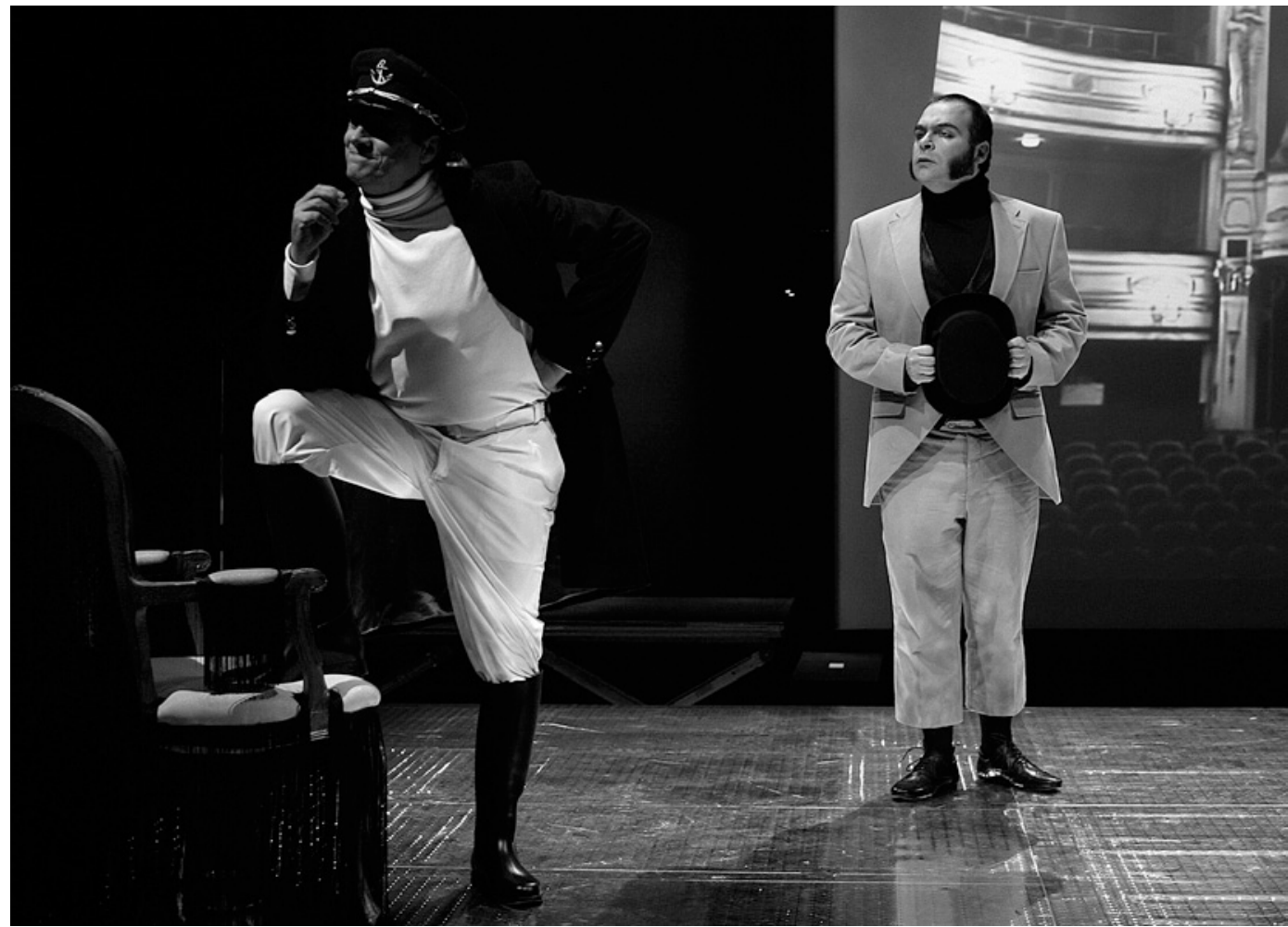

TOM: Estou esfomeado, lan, quero ir para onde haja muita comida. (...) É o que Darwin está aqui a dizer, não é?

IAN: Tom, não podes fazer isso. Moralmente.

TOM: Não percebo essa palavra, lan. (Wertenbaker 1998: 45)

É levantada aqui uma perspectiva da ideia da sobrevivência das espécies (humana, neste caso) como se pudesse implicar a ausência de moral. As ideias de Darwin são usadas para validar um "vale tudo" hipoteticamente inscrito nas leis naturais da nossa evolução.

0 debate ciência/religião também surge, essencialmente e inevitavelmente entre as personagens de Darwin e Fitzroy, com conhecidas divergências nestes assuntos essencialmente após a publicação de $A$ origem das espécies. Cito um pequeno excerto da peça onde isso é abordado:

DARWIN: Sou um naturalista, não um teólogo.

FITZROY: (...) as verdades cientificas existem para revelar as intenções de Deus. (Wertenbaker 1998: 39)

Este debate ciência/religião é também motivo de atenção dramatúrgica em Darwin in Malibu, de Crispin Whittell, estreada em 2003 pelo Birmingham Repertory Theatre. Aqui, Darwin vive em Malibu, na costa Oeste dos EUA, residência para muitas estrelas cinematográficas, 0 que the confere, desde logo, o estatuto de celebridade $e_{\text {, }}$ considerando que a peça decorre na actualidade, muito depois de Darwin ter morrido, o coloca numa espécie de limbo. Os protagonistas são Darwin, o seu amigo e biólogo Thomas Huxley, o bispo de Oxford Samuel Wilberforce e uma jovem chamada Sarah. Sarah é uma personagem enigmática que assume dramaturgicamente, em determinados momentos, o papel de algumas mulheres importantes na vida de Darwin, como é referido na seguinte fala:
DARWIN: Quando estou contigo vejo-te a ti mas também vejo a Annie. Vejo a menina que a Annie nunca chegou a ser. E vejo a Emma uns meses antes de a Annie nascer. És a minha três-em-um. A minha Santissima Trindade. (Whittell 2003: 49)

A morte da filha Annie, com 10 anos, é um tema nesta e noutras das obras estudadas. É vista como um ponto de viragem na relação do cientista com Deus e a religião e, por isso, com enorme potencial dramático. A historiadora e biógrafa de Darwin - Janet Browne - refere que "é possivel que a morte de Annie tenha levado Darwin a inclinar-se finalmente para a descrença. [...]. Como podia um criador bom e benévolo aniquilar uma criança tão inocente? Como podia Deus permitir que uma criança sofresse tanto?" (Browne 2008: 65) Nesta peça encontramos Darwin a afirmar, após mencionar a doença e morte da filha, "Como vês perdi Deus no coração antes de ter perdido Deus na cabeça." (Whittell 2003: 43).

Um tema central na estrutura de Darwin in Malibu é a discussão histórica na BAAS (Browne 2008: 106-107) entre Wilberforce e Huxley, acérrimo defensor da Teoria da Evolução, a propósito da obra A origem das espécies. A peça cria o espaço para os colocar de novo em confronto mas também para criar algo de enorme potencial dramático que não sucedeu na realidade - uma discussão directa entre Darwin e Wilberforce. É, aliás, a necessidade deste encontro por parte de Wilberforce que o move a procurar Darwin e a dizer-Ihe num momento de revelação:

WILBERFORCE: (...) Onde foi que Lhe falhei. Foste tu, Charles! Foste sempre tu! Tenho sido paciente, mas a minha paciência está a acabar. Provoquei este encontro para tentar levar-nos para o Céu. Vim aqui, Charles, para te levar a Cristo. (Whittell 2003: 29)

Há uma ideia essencial que se começa a acentuar à medida que a peça progride, a de que o que distingue o 
Homem dos outros animais é a consciência da morte, e que os livros e as ideias são roupas que vestimos para conseguir viver com essa consciência. Será, portanto, algo que nos une e não que nos separa. Esta imagem é acentuada na cena final onde as páginas d'A origem das espécies, da Biblia e, depois, de muitos outros livros, se misturam no vento de uma tempestade tropical.

É uma imagem idêntica à do final de Inherit the Wind (Herdar o vento) em que o advogado de defesa junta a Origem e a Biblia e as coloca na mesma pasta.

Trumpery foi escrita por um autor, Peter Parnell, que já anteriormente se debruçara sobre a vida de uma personalidade da ciência - o fisico teórico Richard Feynman - na peça QED, de 2002 (Parnell 2002). Estreada pela Atlantic Theater Company, em Nova lorque, em 2007, Trumpery tem Darwin por personagem central e a acção decorre na casa deste, em Kent, em 1858 (1 acto) e 1861 ( $2^{\circ}$ acto). 0 conflito central da peça é a questão da prioridade da descoberta da Teoria da Evolução entre Darwin e Alfred Russel Wallace. Darwin já há alguns anos planeava escrever a obra que o veio a tornar famoso. No entanto, recebeu um dia por correio um ensaio de Wallace onde este estabelecia os principios da evolução por selecção natural. De um momento para o outro Darwin viu-se ultrapassado por alguém que chegara de modo independente às mesmas conclusões que ele. Isto veio precipitar o trabalho de Darwin sobre A origem das espécies. Os seus amigos Thomas Huxley e Joseph Hooker organizaram uma apresentação pública conjunta das ideias de Darwin e Wallace, e um ano e alguns meses mais tarde foi publicado o livro que tornou Darwin famoso.

No primeiro acto, a acção principia com a recepção da carta de Wallace por Darwin onde aquele descreve a Teoria da Evolução quase ipsis verbis. No segundo acto já $A$ origem das espécies foi publicada e Darwin recebe em casa a visita de Wallace, sendo o primeiro representado como sofrendo um enorme peso de consciência pelo modo como foi tratada publicamente a questão da autoria da Teoria da Evolução, onde Wallace foi relegado para um plano marginal. É em torno desta questão de consciência, de moral e ética científica associadas à questão da prioridade da formulação da teoria, que se desenvolve Trumpery, cujo titulo recupera uma expressão usada por Darwin ao discutir esta questão em carta dirigida a Charles Lyell em Junho de 1858:

[...] Mas, não tendo eu antes intenção de publicar qualquer esboço, poderei fazê-lo de modo honrado agora que Wallace me enviou um resumo da sua teoria? Preferiria queimar o meu livro inteiro a que ele ou qualquer outro homem pensasse que me tinha comportado de modo condenável. Não Ihe parece que o ele ter-me enviado este resumo me deixa de mãos atadas? [...] Meu querido amigo, peço desculpa. Esta é uma carta desiludida, influenciada por sentimentos de decepção ${ }^{8}$.
Na peça, é na boca de Huxley que encontramos a defesa do trabalho de Darwin e a extrapolação da teoria da evolução das espécies por selecção natural para o dominio da sociedade humana:

HUXLEY: Competição? Qual o mal nisso?! É disso que o mundo é feito! Tu próprio o provaste! E não esqueças que algo de grandioso emergiu desta competição: o teu livro.

DARWIN: Escrito para vencer Wallace. Para enviar Wallace atirar Wallace para o esquecimento. (Parnell 2009: 42)

0 debate das ideias de Darwin, que mais uma vez e invariavelmente está associado a um debate ciência/religião, tem aqui por interlocutor uma visita da sua casa, o paleontólogo Richard Owen, que viria a ser um feroz opositor à teoria de Darwin. A morte da filha Anne, fechando o primeiro acto, é também, tal como sucede em Darwin in Malibu, um elemento estruturante da peça e das ideias de Darwin, nomeadamente no que toca à sua relação com Deus e a religião:

ANNIE: Mas se nada acontece sem ser pela vontade de Deus, porque é que Ele permite a dor e o sofrimento? (Parnell 2009: 15)

\section{Darwin como "dramaturgo"}

Há algumas peças sobre Darwin que utilizam as próprias palavras do cientista na boca da sua personagem. Não é de estranhar a exploração desta possibilidade pois Darwin foi um prolífico escritor, autor de vários livros científicos com uma prosa reconhecidamente cativante (Browne 2008: 77) e, sobretudo, deixou-nos um enorme legado de cartas trocadas com correspondentes de todo o mundo ${ }^{9}$.

A Universidade de Cambridge, através do seu Darwin Correspondence Project (DCP), colocou em suporte informático a vasta correspondência de Darwin. Em 2007 o DCP financiou a criação de uma "dramatização" baseada nessa correspondência. 0 resultado foi Re:Design, escrita por Craig Baxter e estreada pela Menagerie Theatre Company de Cambridge, em 2007. Re:Design dramatiza alguma da correspondência do cientista nomeadamente com o biólogo norte-americano Asa Gray e o amigo próximo e também biólogo Joseph Hooker (entre outros) entre 1844 - data em que terá mencionado pela primeira vez as suas ideias revolucionárias a Hooker - e 1888 - data da morte de Gray.

Um dos factos dramáticos mais fortes em torno do qual o texto é construído é o momento em que Darwin revela as suas ideias sobre a evolução das espécies como culminar de uma progressiva e cautelosa reflexão consciente do impacto que elas causariam. Um dos excertos (famoso) onde se sente o conflito interior do cientista e se sente o receio da publicação das suas ideias é:

DARWIN: [...] Estou quase convencido - contrariamente à minha opinião inicial - que as espécies não são - é como confessar um assassinio - imutáveis... (Baxter 2007: 3) 


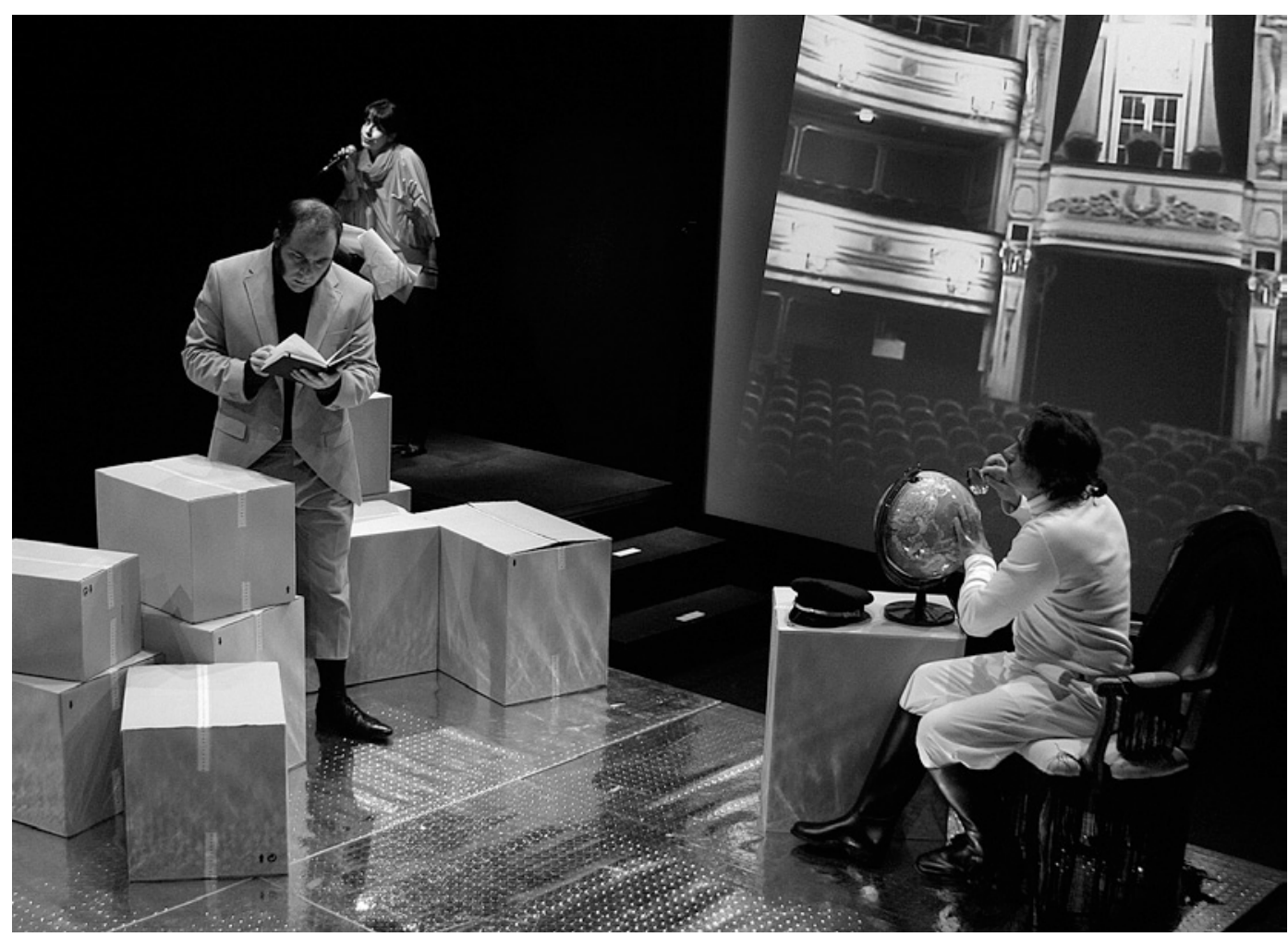

Como seria de esperar, considerando o potencial dramático do tema, esta dramatização da correspondência de Darwin também explorou a argumentação ciência vs religião, sobretudo nas missivas trocadas entre o cientista e Asa Gray, um católico convicto:

GRAY: Na Natureza Orgânica abundam sinais irrepreensiveis e irresistiveis de um designio, e, sendo um sistema ligado e consistente, esta evidência traz a implicação de um designio para tudo. DARWIN: Estou aturdido... reconheço que não consigo ver tão claramente como outros conseguem, e do modo que gostaria, evidências de um designio e de beneficência em todo o lado. Pareceme que existe demasiada miséria no mundo. (Baxter 2007: 15)

0 elemento inovador que Re:Design introduz é o aproveitamento das palavras reais (trocadas?) entre os cientistas, declaradamente com algumas liberdades artísticas na articulação e colagem dessas palavras com o intuito de acentuar uma dinâmica dramática, o que nos oferece uma perspectiva curiosa enquanto

leitores/espectadores ao revelar-nos de forma clara uma dramaticidade intrinseca na realidade aqui tratada.

Outro texto com caracteristicas dramáticas que se apoia na correspondência de Charles Darwin é 0 português que se correspondeu com Darwin. 0 foco desta obra está nas cartas trocadas entre o cientista açoriano Francisco de Arruda Furtado e o cientista inglês entre Junho e Novembro de 1881. Nestas, Darwin, muito cordial, aconselha Furtado quanto a possiviveis investigações que poderá desenvolver no arquipélago dos Açores. 0 cientista português, olhando Darwin como a um mestre, mostrase profundamente agradecido pela atenção que lhe é dispensada. 0 facto de a peça ter o seu primum mobile nesta correspondência sem grande dinâmica torna-a pouco dramática, no sentido de não ter um conflito forte em torno do qual se desenvolva. 0 encontro entre estes dois cientistas aconteceu já na fase final da vida de Darwin, quando o seu grande "momento dramático", a publicação d'A origem das espécies, acontecera já há muitos anos atrás.

No entanto, à semelhança do que sucede nos outros textos estudados, existe referência a esta publicação bem como a outros elementos biográficos de Darwin e do seu trabalho. A peça está organizada em treze quadros, sendo feita nos primeiros oito a caracterização e enquadramento biográfico das duas personagens principais, Darwin e Furtado. Há uma evolução cronológica desde 1855, quando Furtado tinha um ano, até 1881, altura da troca de correspondência entre os dois, alternando os quadros entre o protagonista Darwin e o protagonista jovem Furtado até ao seu encontro epistolar. Aqui, sobretudo no décimo quadro, as perguntas e respectivas respostas articuladas nas sucessivas cartas são entremeadas de forma a juntar as duas personagens num diálogo.

Os principais elementos biográficos de Darwin referenciados no texto são, no campo científico, alguns cientistas antecessores e contemporâneos que influenciaram de certa forma a formulação das suas teorias, como Erasmus Darwin, Lamarck, Wallace, Lyell e Malthus, bem como a viagem no Beagle. No campo pessoal, há várias referências a um Darwin de saúde frágil e ao equacionar de um potencial conflito com a sua doutrina religiosa em diálogo com a esposa, uma católica convicta, como no seguinte excerto:

DARWIN: Eu sei o que pensas e o que temes. Sendo o Homem criado à imagem e semelhança de Deus, quem sou eu para 0 tirar do centro da vida na Terra, pondo em causa a mais divina das criações! Não o quero fazer, sou um homem crente, mas... (Trincão 2009: 36)

A sucessão cronológica dos quadros iniciais, com a dramatização breve de alguns dados biográficos dos dois cientistas, converge para aquele momento em que estes 
se encontram no tempo por intermédio da correspondência que trocaram. No entanto, como este encontro não contém grande potencial dramático, é uma convergência para um momento dramaticamente desinteressante, cujo interesse estará sobretudo na apresentação do praticamente desconhecido Arruda Furtado e das suas investigações ao público - "objectivo central" da obra, nas palavras do autor na introdução. Darwin é aqui, portanto, um pretexto para falar do investigador português.

\section{0 que torna Darwin dramático?}

Após uma análise conjunta destes textos dramáticos onde Darwin serviu de inspiração, poderemos apontar os temas da vida e obra do cientista de que os dramaturgos se apropriaram de modo mais intenso para desenvolverem os seus textos, assim como alguns caminhos utilizados nessa transposição. Podemos identificar essencialmente factos biográficos pessoais e factos biográficos científicos que muitas vezes se interpenetram uma vez que Darwin vivia intensamente o seu trabalho.

\section{A vida pessoal}

Os factos da vida pessoal de Darwin surgem essencialmente nas peças em que Darwin surge como personagem. Os problemas de saúde que, de modo quase permanente sobretudo após a sua longa viagem no Beagle, o afectavam, são referidos e utilizados como forma de ajudar a caracterizar a personagem. A forte religiosidade da esposa Emma Darwin, assim como a morte por doença da filha Anne, como vimos, são elementos biográficos utilizados pelos dramaturgos para abordar o questionar de Darwin relativamente à sua crença em Deus e os possiveis conflitos do cientista e do seu trabalho com a religião.

A viagem no Beagle constituiu um factor preponderante na formação de Darwin como pessoa e como naturalista, uma vez que Ihe permitiu recolher as bases para o que viria a ser a sua enorme contribuição para a Ciência. Factos dessa viagem são também usados para caracterizar a personagem Darwin. Em After Darwin por exemplo, a viagem no Beagle é um elemento central da peça. Esta desenvolve-se em torno da relação de Darwin com o Capitão Fitzroy, tanto durante como após a viagem aproveitando e acentuando as diferenças de opinião dos dois homens, sobretudo no tocante às ideias sobre evolução e as implicações destas nas crenças de cada um. 0 suicidio de Fitzroy é um facto que abre a peça e que dá a sensação de funcionar como motor da intriga, como se esta se desenvolvesse na procura de uma justificação para esse acto derradeiro do capitão.

\section{A teoria da evolução por selecção natural}

Há diversas referências a algumas influências científicas que Darwin reconhecidamente sofreu para o desenvolvimento das suas teorias, e que surgem nas falas das personagens das peças estudadas. Uma assinalável é Thomas Malthus que, através do seu An Essay on the Principle of Population (Ensaio sobre o princípio da população) (1798), terá sido uma peça fundamental para Darwin no desenvolvimento da sua Teoria da Evolução (Browne 2008: 53-54).

Como ilustração deste facto, cito um excerto de diálogo de Trumpery entre Thomas Huxley e Darwin, onde o primeiro questiona o segundo a propósito da sua famosa teoria:

HUXLEY: Como? Como chegaste a tudo isto? DARWIN: Chegou-me de Malthus. Uma vasta superprodução de nascimentos individuais na natureza mas, no entanto, sem um aumento apreciável da população. Por que razão não atingimos o limite? Por causa da morte, claro. Mas quem vive e quem morre? (Parnell 2009: 25)

A "Teoria da evolução por selecção natural", publicada em A origem das espécies, é, sem qualquer dúvida, o elemento central comum a todas as peças estudadas. Ele constitui o ponto mais alto da carreira científica de Darwin e essa importância reflecte-se nas diferentes abordagens dramatúrgicas aqui analisadas. A sobrevivência do mais apto, ideia associada à de selecção natural, abre-se a analogias por parte dos dramaturgos, tal como Darwin havia feito com Malthus, mas no sentido inverso - da natureza para a sociedade humana. Tal acontece no exemplo de After Darwin (Segundo Darwin) atrás referido, onde um dos actores decide abandonar a peça que constroem por Ihe ser oferecida uma possibilidade supostamente mais favorável de participar num filme; também acontece em Trumpery, onde é o próprio Darwin quem compete com Alfred Wallace pela prioridade da publicação da sua teoria; e é uma ideia subjacente também a todas as manobras políticas de Chimera, sendo aliás, explicitamente afirmada logo nas primeiras palavras do texto.

Para além das ideias revolucionárias contidas na nova teoria enunciada por Darwin, há alguns factos históricos relacionados com a publicação de $A$ origem das espécies que mereceram também a atenção dos dramaturgos. Um deles é o longo tempo que Darwin levou para publicar a obra. Desde o primeiro alinhavar escrito da sua teoria em 1844 até à publicação passaram 15 anos. A possibilidade de questionar o porquê desta demora singular é aproveitada, por exemplo, por Re:Design, cuja acção cronológica principia precisamente naquele ano de 1844 ou Chimera, onde o protagonista afirma:

ROY: (...) Charles Darwin. Ai está um tipo que sabia muito bem como protelar. Tropeçou na própria essência da vida, mas decidiu guardálo para si. Não quis dizer aos amigos que descendiam de algas e não de anjos. Não aguentava ter de partir o devoto coração da esposa. (...) (Lill 2007: 7)

\section{"A prioridade"}

Outro facto histórico relacionado com a publicação da sua obra é a questão da prioridade com Alfred Russel 
Wallace relativa à teoria da evolução. 0 facto de a publicação ter sido precipitada por Darwin ter tido conhecimento das ideias semelhantes de Wallace e do desconforto manifestado pelo primeiro relativamente a este assunto em diversas cartas trocadas com amigos, são dados com potencial dramatúrgico. Trumpery é, como vimos, alicerçada nesta questão.

Em Re:Design, a escolha e organização da correspondência que serve de base à peça também coloca ênfase nesta questão da prioridade utilizando palavras de Darwin a este propósito em várias cartas enviadas a Lyell em Junho de 1858, como por exemplo:

[...] Deveria estar agora extremamente contente por publicar a minha visão geral. Mas não me convenço poder fazê-lo de modo honrado, [...] sabendo que Wallace está em campo... / Parece-me demasiado duro ser assim compelido a perder a minha prioridade de já muitos anos. (Baxter 2007: 10)

\section{0 embate ciência vs religião}

Outro facto histórico relacionado com a publicação d' $A$ Origem das Espécies que é objecto de exploração dramatúrgica nas obras analisadas é a célebre troca de argumentos entre Thomas Huxley e o bispo Samuel Wilberforce que, como refere Janet Browne, "[t]ornou-se um símbolo do embate violento entre ciência e religião [...]" (Browne 2008: 106). Em Darwin in Malibu, como já vimos, este debate funciona como inspiração essencial para o desenvolvimento da peça, mas está também presente em Trumpery, como por exemplo neste excerto em que Darwin e Huxley trocam argumentos com o paleontólogo Richard Owen:

\section{DARWIN: 0 Homem!? Temos de falar do Homem!?}

OWEN: Sim! 0 Homem. Não os dinossauros ou as alforrecas. Porque o Homem é o que em última análise interessará ao bispo de 0xford. HUXLEY: Quero lá saber do bispo de Oxford! (Parnell 2009: 23)

Este embate entre ciência e religião é elemento fundamental para a dinâmica dramática em praticamente todas as obras analisadas, embora variando os representantes de cada um dos lados. Do lado da religião encontramos como oradores Owen e Wilberforce, também Asa Gray (com um discurso mais equilibrado) em Re:Design, o Capitão Fitzroy de After Darwin e o deputado conservador de Chimera. Do lado da ciência encontramos, para além de Darwin, Huxley e Hooker, a cientista Nell de Chimera. E também, de um e outro lado respectivamente, os advogados de acusação e defesa de Inherit the Wind.

\section{A natureza e a ideia de Deus}

Há ainda outros elementos que mereceram desenvolvimento nas várias obras analisadas. Um, muito curioso, é o jardim como elemento inspirador na vida de Darwin. 0 cientista cuidava do seu próprio jardim na sua casa em Down, de onde ia realizando experiências e recolhendo dados para as suas investigações em Zoologia e Botânica. Em Trumpery o jardim é um elemento cenicamente presente e um espaço importante no decorrer da acção. A peça termina com Darwin ajoelhado na terra a observar uma minhoca e, depois, a tentar imitar um pássaro que canta algures por ali (Parnell 2009: 51). É o espaço de ligação de Darwin com a natureza. Eventualmente um espaço de reunião com a ideia de Deus, é ali que o vemos ajoelhar-se. Também Nell, a cientista de Chimera (inglesa, como Darwin), trata empenhadamente do seu jardim. Este local ganha um forte poder simbólico quando a cientista toca no ponto sensivel do debate ciência/religião - a eventual fragilização da ideia de Deus:

NELL: Sabe por que razão os britânicos têm conseguido evitar todos estas discussões incómodas sobre o Criacionismo versus Darwinismo? Porque os nossos jardins tomam o lugar de Deus. Criamos o nosso pequeno Éden e seguimos em frente. (Lill 2007: 76)

Nas duas peças estudadas onde a acção decorre no presente, After Darwin e Chimera, são também criadas relações das personagens com doenças e distúrbios genéticos como a SIDA, a síndrome de Down, o Autismo, que poderão provocar uma reflexão quando relacionadas com as teorias de Darwin, nomeadamente a de selecção natural.

\section{Livro como objecto de ideias}

Finalmente, uma última ideia que emerge das obras assinaladas: a utilização simbólica do livro como objecto de ideias. Essa utilização é explícita, como já vimos, em Inherit the Wind e Darwin in Malibu, onde os livros da Biblia e d'A origem das espécies se confrontam fisicamente. Nesta última peça juntam-se também como adereços importantes um romance e um jornal, cujos conteúdos vão influenciando o decorrer da acção e cujas páginas se misturarão, no final, com as daqueles outros dois livros. Também em Chimera temos a presença física d'A origem das espécies, de onde é lido um excerto no início da peça, e que virá a ser oferecido pela cientista ao jornalista no final. 0 livro enlaça a peça, surge no início dos dois actos e no final, e isto torna-o uma referência para os temas ali discutidos.

Também After Darwin começa com uma personagem a brandir um livro: é Fitzroy que recrimina Darwin com a Bíblia numa mão, numa clara alusão ao episódio histórico em que tal terá realmente sucedido, na referida reunião da BAAS. Na cena final desta peça os livros ganham a dimensão de suporte da evolução do pensamento humano. Uma das personagens percorre com os olhos uma prateleira invisível de livros e vai citando títulos como que a lê-los nas lombadas, fazendo um percurso pela evolução do nosso conhecimento sobre a evolução das espécies. 
As peças teatrais onde Darwin é presença relevante não se limitam às abordadas neste artigo de modo mais detalhado. A estas somam-se, por exemplo, as duas peças sobre Darwin (onde este surge como personagem) estreadas em Lisboa pela companhia A Barraca em 2007 e 2009, respectivamente Darwin e o canto dos canários cegos, de Murilo Dias César, e 0 professor de Darwin, de Helder Costa (Costa 2009), que constituem outros exemplos da recepção de Darwin no teatro feito em Portugal. Ou ainda como exemplo de uma peça financiada pela Alfred Sloan Foundation, Tooth and Claw (Dente e garra), de Michael Hollinger (Hollinger 2010), estreada em 2004 pela Arden Theatre Company em Filadélfia, E.U.A., sobre o conflito (ocorrido em 1995) entre pescadores das Galápagos e defensores da preservação dos ecossistemas naturais destas ilhas. A questão da sobrevivência das espécies, neste local tão simbólico para a Teoria da Evolução, é motivo central nesta peça onde Darwin está presente através do seu legado científico.

Da análise dos textos estudados fica claro que o potencial dramático de Darwin está fortemente ligado à sua publicação mais famosa, A origem das espécies, tanto pela força e impacto das ideias ali veiculadas como pelas fortes reacções que provocou e ainda provoca. Não é de surpreender portanto, no contexto recente de aproximação do teatro a temas científicos, a apropriação pelo palco artístico de um legado científico revolucionário para a Humanidade e de uma figura icónica do mundo da Ciência.

É isso que torna Darwin dramático. Isso, e o facto de ser humano.

\section{Referências bibliográficas}

BARNETT, David (2005), "Reading and Performing Uncertainty: Michael Frayn's Copenhagen and the Postdramatic Theatre", Theatre Research International, Vol. 30, Nr. 2, pp. 139-149.

BAXTER, Craig (2007), Re:Design, disponivel on-line no endereço http://www.darwinproject.ac.uk/ dramatisation-of-thecorrespondence. A versão analisada foi a de 2007, para três actores. BEGORAY, D. \& Stinner, A. (2005), "Representing Science Through Historical Drama - Lord Kelvin and the Age of The Earth Debate", Science \& Education, Vol. 14, Nr. 3-5, pp. 457-471.

BRECHT, Bertolt (1970), Vida de Galileu, trad. Yvette Centeno, Lisboa, Portugália Editora.
BROWNE, Janet (2003), "Charles Darwin as a celebrity", Science in Context, Vol. 16 (1/2), pp. 175-194.

-- (2008), A origem das espécies de Charles Darwin, trad. Ana Falcão Bastos e Cláudia Brito, Lisboa, Gradiva.

COSTA, Helder (2009), O professor de Darwin, Lisboa, Gradiva.

DARWIN, Charles (2005), A origem das espécies, trad. Dora Batista, Mem Martins, Publicações Europa-América.

DJERASSI, Carl (2002), "Science and Theatre", Interdisciplinary Science Reviews, Vol. 27, Nr. 3, Autumn, pp. 193-201.

DÜRRENMATT, Friedrich (1965), A visita da velha senhora e Os fisicos, trad. Irene Issel e Jorge de Macedo, Lisboa, Portugália Editora.

HOLLINGER, Michael (2010), Tooth and Claw, New York, Dramatists Play Service, Inc.

LAWRENCE, J. \& Lee, R. L. (2003), Inherit the Wind, New York, Ballantine Books.

LILL, Wendy (2007), Chimera, Vancouver, Talonbooks.

MAGNI, Francesca (2002), "The Theatrical Communic-action of Science", JCOM - Journal of Science Communication, Nr.1, March, pp. 1-14.

MONTENEGRO, Mário (2007), Texto dramático de tema cientifico: o caso particular de Carl Djerassi, tese de mestrado, Porto, Universidade do Porto.

PARNELL, Peter (2002), QED. A play, New York, Applause Theatre \&t Cinema Books.

-- (2009), Trumpery, New York, Dramatists Play Service, Inc.

ROSE, S. P. R. (2003), "How to (or not to) Communicate Science", Biochemical Society Transactions, Vol. 31, Part 2, pp. 307-312.

SHEPHERD-BARR, Kirsten (2003), "From Copenhagen to Infinity and Beyond: Science Meets Literature on Stage", Interdisciplinary Science Reviews, Vol. 28, Nr.3, pp. 193-199.

-- (2006), Science on Stage: From Doctor Faustus to Copenhagen, Princeton, Princeton University Press.

-- (2008), "Darwin on stage: evolutionary theory in the theatre", Interdisciplinary Science Reviews, Vol. 33, Nr. 2, pp. 102-115.

SMOCOVITIS, Vassiliki B. (1999), "The 1959 Darwin Centennial Celebration in America", Osiris, $2^{\text {nd }}$ series, Vol. 14, pp. 274-323.

SNOW, C. P. (1959), The Two Cultures, Cambridge, Cambridge University Press.

TRINCÃO, Paulo (2009), o português que se correspondeu com Darwin, Lisboa, Gradiva.

WERTENBAKER, Timberlake (1998), After Darwin, London, Faber and Faber. WHITELL, Crispin (2003), Darwin in Malibu, London, Methuen.

ZEHELEIN, Eva-Sabine (2009), Science: Dramatic. Science Plays in America and Great Britain, 1990-2007, Heidelberg, Winter. 